\title{
Combate à fome no Brasil: uma análise histórica de Vargas a Lula
}

\author{
Fighting hunger in Brazil: a historical analysis \\ from Presidents Vargas to Lula
}

Francisco de Assis Guedes de VASCONCELOS'

\section{R E S U M O}

Este estudo consiste de uma análise histórica dos programas de combate à fome no Brasil no período de 1930 a 2003. Como critérios metodológicos de análise foram estabelecidos três cortes transversais, correspondentes a contextos específicos da trajetória da política social de alimentação e nutrição no Brasil: 1930-1963; 1964-1984; 1985-2003. Em cada corte investigado, procurou-se identificar e descrever os programas de alimentação e nutrição e evidenciar as suas principais categorias discursivas. A análise dos programas aponta importantes mudanças, sobretudo depois da metade dos anos 1980. A partir desse período, a política de combate à fome no país transitou do planejamento autoritário ao participativo; da centralização à descentralização administrativa; da universalização à focalização de benefícios; do controle estatal ao social; da distribuição de alimentos à transferência de renda em dinheiro; do financiamento público à parceria entre público e privado, entre sociedade civil e Estado.

Termos de indexação: fome, política social, política pública, programas e políticas de alimentação e nutrição.

\section{A B S T R A C T}

This study consists of a historical analysis of the programmes aimed at fighting hunger in Brazil, in the period from 1930 to 2003. As methodological criteria for this analysis three transverse sections were established, corresponding to specific contexts in the history of the social policy on food and nutrition in Brazil: 1930-1963; 1964-1984 and 1985-2003. The survey attempts to identify and describe the food and nutrition programmes, showing the main discursive categories in each section studied. An analysis of the programmes shows important changes, above all, since the mid-eighties. As from this point, the policy for fighting hunger in the country passed from authoritarian planning to partnership; from centralized to decentralized administration; from universal to specific benefits; from State control to social control; from distribution of food to transference of income in cash; from public financing to public and private partnerships between the civilian society and the State.

Indexing terms: hunger, social policy, public policy, nutrition programmes and policies.

\footnotetext{
1 Departamento de Nutrição, Centro de Ciências da Saúde, Universidade Federal de Santa Catarina. Campus Universitário Trindade, 88040-900, Florianópolis, SC, Brasil. E-mail: <fguedes@floripa.com.br>.
} 


\section{N T R O D U Ç Ã O}

Alguns autores apontam que a questão da fome no Brasil tem suas raízes no processo histórico de formação da sociedade brasileira, atribuindo sua emergência ao início do período colonial1,2. Entretanto, observa-se que os primeiros estudos sistematizados sobre os hábitos alimentares e as doenças carenciais relacionadas à alimentação da população brasileira só começaram a surgir a partir do século XIX, por meio das teses apresentadas às faculdades de Medicina existentes até então, Bahia e Rio de Janeiro ${ }^{3,4}$.

Sendo assim, na literatura investigada, entre os primeiros relatos sobre o flagelo da fome e de seu enfrentamento, destacam-se os trabalhos do farmacêutico cearense Rodolfo Marcos Teófilo, publicados entre 1880 e 1890 . Nesses relatos, segundo análises realizadas por Josué de Castro ${ }^{5}$, encontram-se preciosos registros das mais diversificadas formas de penúria e de fome provocadas pelas secas sobre os sertanejos nordestinos. Por outro lado, apesar de ações estatais voltadas para a questão da alimentação da população terem sido conduzidas desde o início do período colonial' ${ }^{\text {, }}$ pode-se afirmar que os primeiros instrumentos específicos de política social de alimentação e nutrição foram instituídos apenas ao longo da Ditadura Vargas (1937-1945). Ou seja, a emergência da política de alimentação e nutrição, um setor específico das políticas sociais do Estado capitalista brasileiro, ocorreu, portanto, ao longo do processo de transição do Estado liberaloligárquico para o Estado intervencionistaburguês ${ }^{6-9}$.

Neste artigo pretende-se realizar uma análise histórica dos programas de combate à fome no Brasil no período de 1930 a 2003. Ao longo desse eixo longitudinal, como critérios metodológicos de análise foram estabelecidos, de forma intencional, três cortes transversais correspondentes a contextos específicos da trajetória da política social de alimentação e nutrição no Brasil: 1930-1963; 1964-1984 e 1985-2003. O primeiro corte corresponde ao período de emergência dos primeiros instrumentos dessa modalidade de política social, delineados sob a influência de Josué de Castro e seus pares. O segundo corresponde às tentativas de incorporação de técnicas de planejamento nutricional ao planejamento econômico, conduzidas sob a direção do Instituto Nacional de Alimentação e Nutrição (INAN), no bojo da tecnoburocracia da Ditadura Militar. O terceiro corresponde aos últimos dezenove anos de tentativas de democratização e modernização da sociedade brasileira e de buscas de alternativas para superação dos seus graves dilemas sociais. Em cada um desses cortes, procura-se identificar e descrever os instrumentos de política social de alimentação e nutrição e apontar as suas principais categorias discursivas e operacionais.

Parte-se da concepção que define política social de alimentação e nutrição como ações estatais voltadas para a produção, comercialização e consumo de alimentos para determinados segmentos sociais, e do pressuposto de que as políticas sociais (entre elas, a política de alimentação e nutrição) são produtos da correlação de movimentos simultâneos de acumulação de capital, de forças sociais e da forma que o Estado assume em determinadas conjunturas ${ }^{10}$. Ou seja, as distintas formas de intervenção estatal na área de alimentação e nutrição são construídas, desconstruídas e/ou reconstruídas a partir do jogo de interesses econômicos, sociais e políticos que se opera entre os distintos segmentos sociais de cada conjuntura examinada.

\section{A fome acompanha o processo de urbanização e industrialização do país (1930 a 1963)}

No pós-30, sobretudo no período de 1937-1945, dentre as transformações econômicas, políticas e sociais ocorridas no Brasil11,12, verificou-se a emergência do processo simultâneo de descoberta científica da fome (o surgimento da ciência da Nutrição); de criação da prática profissional em Nutrição (criação dos cursos para formação do nutricionista) e de instituição da política social de alimentação e nutrição².

Nesse contexto, as precárias condições de vida da classe trabalhadora foram amplamente 
denunciadas. Por exemplo, em 1932, Josué de Castro, ao realizar um estudo sobre as condições de vida de famílias operárias do Recife, observou que o consumo alimentar, à base de açúcar, café, charque, farinha, feijão e pão, fornecia apenas cerca de 1645 calorias; custava cerca de 71,6\% do valor do salário; era pobre em vitaminas e sais minerais e gerava alta mortalidade e baixa esperança de vida ${ }^{13}$. Os resultados desse estudo tiveram ampla divulgação nacional, provocando a realização de estudos similares, inclusive daquele que serviu de base para a regulamentação da lei do salário mínimo ${ }^{5,14}$.

Portanto, no transcurso do Estado Novo (1937-1945), a partir da instituição do salário mínimo, da criação do Serviço de Alimentação da Previdência Social (SAPS) e da Comissão Nacional de Alimentação (CNA), entre outras intervenções estatais (Anexo 1), registra-se a emergência da política social de alimentação e nutrição, denotando que o Estado brasileiro procurava se aparelhar de novos mecanismos que Ihe garantissem legitimidade e hegemonia ${ }^{10}$.

Por meio do Decreto-Lei ㄲo 2.162, de 1 으 de maio de 1940, foi instituído o salário mínimo no Brasil, anunciado à Nação em discurso realizado pelo presidente Vargas:

[...] Assinamos hoje, um ato de incalculável alcance social, a lei que fixa o salário mínimo para todo o país. Trata-se de antiga aspiração popular, promessa do movimento revolucionário de 1930, agora transformada em realidade depois de longos e apurados estudos. Procuraremos por esse meio assegurar ao trabalhador remuneração eqüitativa, capaz de garantir-lhe o indispensável para o seu sustento e da própria família, estabelecendo um padrão mínimo de vida para a grande maioria da população, aumentando no decorrer do tempo os índices de saúde e de produtividade que auxiliarão a solução de importantes problemas que retardam a marcha do nosso progresso (Vargas, discurso de 19 de maio de 1940, apud Castro' ${ }^{15}$, p.118).
Em relação à alimentação, o Decreto-Lei no 399, de 30 de abril de 1938, estabeleceu a chamada ração essencial mínima que seria composta, em quantidade e qualidade, dos alimentos necessários ao atendimento das necessidades nutricionais de um trabalhador adulto $^{14,16}$. As falácias e contradições do discurso que regulamentou o salário mínimo e estipulou a ração essencial mínima, entretanto, foram emergindo a partir do momento de sua instituição. Assim, entre tais falácias e contradições é preciso observar que ao longo da sua história o valor do salário mínimo não tem sido suficiente nem para satisfazer as necessidades mínimas e individuais do trabalhador, uma vez que os seus reajustes foram fixados muito abaixo do custo de reprodução da força de trabalho. Sendo assim, para adquirir a ração essencial mínima o trabalhador precisaria elevar significativamente o tempo de trabalho necessário ${ }^{14,16-18}$

O SAPS, por sua vez, foi criado pelo Decreto-Lei ํo 2.478, de 5 de agosto de 1940, tendo como objetivo principal: "assegurar condições favoráveis e higiênicas à alimentação dos segurados dos Institutos e Caixas de Aposentadorias e Pensões subordinados ao Ministério do Trabalho, Indústria e Comércio"15 (p.195). No decorrer de sua vigência (1940 a 1967), foi responsável por uma infinidade de ações no campo da nutrição. Na área da assistência nutricional promoveu a instalação dos restaurantes populares no Rio de Janeiro, São Paulo e outras cidades, com o objetivo de oferecer aos trabalhadores urbanos uma alimentação equilibrada e por preço acessível. Na área de abastecimento alimentar promoveu a criação dos postos de subsistência destinados à comercialização de gêneros de primeira necessidade a preço de custo. A essas ações se acrescenta uma série de outras, tais como atividades de educação nutricional, tendo como objetivos a formação de hábitos alimentares saudáveis e a melhoria do estado nutricional da população; a criação de cursos de treinamento e formação de recursos humanos e a realização de estudos e pesquisas nesse campo $0^{6,7,15}$. 
A CNA, por outro lado, foi criada em fevereiro de 1945 pelo Decreto-Lei no 7.328. Vinculada inicialmente ao Conselho Federal de Comércio Exterior, em 1949, foi transferida para o Ministério da Educação e Saúde e, apenas em 1951, foi regulamentada como órgão responsável por assistir o governo na formulação da política nacional de alimentação. Ao longo de sua existência (1945-1972), entre os seus objetivos destacam-se: estudar e propor normas da política nacional de alimentação; estudar o estado de nutrição e os hábitos alimentares da população brasileira; acompanhar e estimular as pesquisas relativas às questões e problemas de alimentação; trabalhar pela correção de defeitos e deficiências da dieta brasileira, estimulando e acompanhando as devidas campanhas educativas; e concorrer para o desenvolvimento da indústria de alimentos no Brasil. Entre as suas realizações merece destaque a promulgação, em 1953, do Primeiro Plano Nacional de Alimentação e Nutrição. Esse plano pode ser considerado um embrião do planejamento nutricional brasileiro e suas ações se voltavam, prioritariamente, à assistência alimentar e nutricional do grupo materno infantil e, em segundo plano, aos escolares e trabalhadores ${ }^{6,7}$.

Na seqüência, entre o Plano SALTE (saúde, alimentação, transporte e energia) de Gaspar Dutra (1946-1950), o retorno do populismo de Getúlio Vargas (1951-1954), o desenvolvimento rápido do Plano de Metas de Juscelino Kubitschek (1955-1960) e as reformas de base de João Goulart (1961 - março de 1964), a questão da intervenção estatal em alimentação e nutrição materializou-se pela continuidade das ações do SAPS; da criação, em 1954, do embrião do atual Programa Nacional de Alimentação Escolar (PNAE) e do início dos programas de assistência nutricional às gestantes, nutrizes e crianças menores de cinco anos de idade desenvolvidos pela CNA. Esses programas estiveram intimamente articulados às organizações internacionais e aos programas internacionais de ajuda alimentar criados no pós-Segunda Guerra Mundial, tais como a Food and Agriculture Organization (FAO), o
United Nations International Children Emergency Fund (UNICEF), o Programa de Alimentos para a Paz, da Agency for International Development (USAID) dos Estados Unidos da América e o Programa Mundial de Alimentos (PMA) 6,7,9.

Nos anos 1946-1963, ressaltam-se a propagação do discurso de combate à fome no contexto mundial e no Brasil e a criação das primeiras organizações não governamentais (ONG) com propósitos humanitários de combate à fome, a exemplo da Associação Mundial de Luta Contra a Fome (ASCOFAM). Sendo assim, em 1946, ao lançar o clássico Geografia da Fome, além de traçar o primeiro mapa da fome no país, Josué de Castro analisava os seus principais determinantes e apontava os caminhos para a sua superação:

Esta dramática situação alimentar (...) impõe a necessidade inadiável de uma política alimentar mais efetiva, que não seja apenas de paliativos e de correção das falhas mais gritantes através de programas simplesmente assistenciais. Impõe-se uma política que, acelerando o processo de desenvolvimento, quebrando as mais reacionárias forças de contenção que impedem o acesso à economia do país a grupos e setores enormes da nacionalidade, venham (SIC) a criar os meios indispensáveis à elevação dos nossos padrões de alimentação ${ }^{5}$ (p.304).

Uma década depois, em 1957, foi fundada a Associação Mundial de Luta Contra a Fome, com sede em Genebra (Suíça) e sob a presidência de Josué de Castro. De acordo com seu estatuto, a entidade foi criada com os objetivos de promover, encorajar e organizar no mundo a luta contra a fome, notadamente despertando, desenvolvendo, apoiando, difundindo, preparando, supervisionando, realizando, direta ou indiretamente, estudos, pesquisas, iniciativas, atividades e ações de natureza a fazer conhecer, diminuir ou eliminar, direta ou indiretamente a fome no mundo, isto é, sem nenhuma limitação ${ }^{19}$ (p.37). No Brasil a 
atuação da ASCOFAM evidenciou-se com a criação, em 1958, da sua delegacia regional em Recife ${ }^{19,20}$. Em 1959, a FAO aprovou a realização da Campanha Mundial de Combate à Fome, a ser conduzida entre 1960 e 1965. A delegacia da ASCOFAM de Pernambuco desenvolveu, nesse período, em articulação com outros órgãos, uma série de atividades dentro dos propósitos estipulados por esta campanha ${ }^{20}$.

As distintas análises realizadas sobre a política social de alimentação e nutrição no período de 1930-1963, reservadas as particularidades e os diferentes enfoques teórico-conceituais, apontam que essa modalidade de intervenção estatal cumpriu de forma articulada objetivos sociais, econômicos e ideológicos. Por exemplo, algumas análises sobre a instituição do salário mínimo, o fornecimento de refeições equilibradas e a garantia de abastecimento alimentar aos previdenciários dos centros urbano-industriais emergentes apontam que, frente à necessidade de incorporação, por parte dos trabalhadores, dos valores e da ideologia que caracterizam as relações e o processo de trabalho capitalista industrial, e à necessidade de idealização de uma imagem do Estado pai-protetor, esses instrumentos cumpriram um papel de atenuação dos conflitos sociais gerados pelo processo de exploração do trabalho que, em última instância, determina a produção e reprodução da fome $e^{6-9,15}$.

Em relação à emergência dos programas de assistência alimentar e nutricional ao grupo materno infantil e aos escolares, as distintas análises realizadas sugerem que a atenção deve ser direcionada, particularmente, para os seus objetivos econômicos e ideológicos. São apontados vários indícios que esses programas constituíram mecanismos de ampliação do mercado internacional de realização de mercadorias, procurando padronizar hábitos e práticas alimentares de acordo com os interesses de acumulação do capital. A introdução do leite em pó e desengordurado, por exemplo, por meio dos programas internacionais de ajuda alimentar, tornou evidente o objetivo econômico. Ou seja, a ajuda não acontecia de forma monetária (o que poderia estimular a produção e o consumo local de alimentos básicos in natura ou processados), mas de forma de valor de uso, por meio do escoamento do excedente de produção que não havia conseguido se realizar em mercadoria ou se transformar em capital. Por outro lado, tais programas se articulavam ao projeto de utilização do alimento como arma de dominação e da fome dos países dependentes como objeto de exploração, cujos objetivos políticos eram atenuar e reprimir os movimentos sociais de caráter socialista ${ }^{6-9,21,22}$.

Enfim, de 1930 a 1963, período em que o país iniciava o seu processo de urbanização e industrialização, o perfil epidemiológico nutricional brasileiro caracterizava-se, sobretudo, pela elevada ocorrência das doenças nutricionais relacionadas à miséria, à pobreza e ao atraso econômico, representadas pela desnutrição energético-protéica (DEP) e pelas carências nutricionais específicas como as deficiências de vitamina A (hipovitaminose A), de ferro (anemia ferropriva) e de iodo (bócio). Portanto, foi mediante a Geografia da Fome, delineada por Josué de Castro e seus pares, que o Estado Populista brasileiro, particularmente no período dirigido por Vargas, tomou a questão nutricional como uma das principais temáticas de sua agenda.

\section{O bolo cresceu, mas a fome aumentou: as contradições do milagre brasileiro (1964 a 1984)}

Após um período de recessão econômica que se estendeu de 1962 a 1967, entre 1968 e 1974 o país vivenciou uma fase de retomada da expansão econômica, conhecida por milagre brasileiro, configurada em elevadas taxas de crescimento que superou a média dos $11 \%$ anuais. Ao final de 1974, entretanto, os sintomas de esgotamento desse padrão de acumulação, evidenciados por alguns indicadores econômicos, tais como a queda do Produto Interno Bruto (PIB), atestavam o seu melancólico fim. Dados sobre a 
distribuição da renda atestavam que além de crescer e não ser dividido, o bolo prometido pelos primeiros governos da Ditadura Militar instalada em 1964 havia se reconcentrado ${ }^{11}$. A degradação das condições de vida das massas trabalhadoras excluídas do processo de crescimento econômico foi atestada por vários estudos. Em 1974/1975, o Estudo Nacional de Despesas Familiares (ENDEF) atestava que $67,0 \%$ da população apresentava um consumo energético inferior às necessidades nutricionais mínimas recomendadas pela Organização Mundial de Saúde (OMS). Como conseqüência, 46,1\% dos menores de cinco anos, $24,3 \%$ dos adultos e idosos brasileiros do sexo masculino e $26,4 \%$ do feminino apresentavam desnutrição energético-protéica11,23,24 .

No cenário internacional, assistiu-se nesse período a um contexto de colapso do capitalismo, no qual a questão da fome mundial ressurgiu com maior intensidade a partir da controvertida crise mundial de alimentos ${ }^{7,21}$. A partir dessa conjuntura, organismos internacionais, como a OMS, a FAO e o UNICEF, passaram a defender a necessidade da incorporação do planejamento nutricional ao planejamento econômico dos países do Terceiro Mundo, em particular, dos países latino-americanos. No Brasil, surgem os I e II Planos Nacionais de Desenvolvimento (PND), incorporando ao planejamento econômico instrumentos de políticas sociais. Dentro desse contexto, por meio da Lei no 5.829, de 30/11/72, foi criado o Instituto Nacional de Alimentação e Nutrição. Sob a tutela do INAN, em março de 1973 foi instituído o I Programa Nacional de Alimentação e Nutrição (I PRONAN), cujas diretrizes pautavam-se no I PND. Em fevereiro de 1976 foi instituído o II PRONAN, que deveria ter duração coincidente com o II PND (1975-1979), mas em função da não aprovação do III PRONAN foi prorrogada sua execução até $1984^{7,25}$.

Ao longo desse período, o INAN pautou-se no desenvolvimento de três linhas de atuação: 1) Suplementação alimentar a gestantes, nutrizes e crianças de zero a seis anos; a escolares de sete a catorze anos e a trabalhadores de mais baixa renda; 2) Racionalização do sistema de produção e comercialização de alimentos, com ênfase no pequeno produtor; e 3) Atividades de complementação e apoio. A linha de suplementação alimentar foi constituída pelo desenvolvimento dos seguintes programas: 1) Programa de Nutrição em Saúde (PNS), desenvolvido pelo Ministério da Saúde por intermédio das Secretarias Estaduais de Saúde; 2) Programa de Complementação Alimentar (PCA), desenvolvido pelo Ministério da Previdência e Assistência Social por intermédio da Legião Brasileira de Assistência (LBA); 3) Programa Nacional de Alimentação Escolar (PNAE), desenvolvido pelo Ministério da Educação e Cultura por intermédio da Campanha Nacional de Alimentação Escolar e 4) Programa de Alimentação do Trabalhador (PAT), desenvolvido pelo Ministério do Trabalho por intermédio do Departamento Nacional de Saúde e Segurança do Trabalhador. Na linha de racionalização do sistema de produção e comercialização de alimentos destacou-se o Programa de Abastecimento de Alimentos Básicos em Áreas de Baixa Renda (PROAB), coordenado pelo INAN e executado pela Companhia Brasileira de Alimentos (COBAL) e Secretarias Estaduais de Saúde e Agricultura. E na linha de complementação e apoio foi desenvolvida uma série de atividades de combate às carências nutricionais específicas pelo enriquecimento de alimentos de consumo corrente; apoio de estudos e pesquisas; capacitação e aperfeiçoamento de recursos humanos e desenvolvimento de infra-estrutura de distribuição de alimentos (Anexo 1) ${ }^{25}$.

Nesse segundo corte analisado, sobretudo no período 1964-1974, embora agravadas as condições de miséria e de fome no país, verifica-se um abrandamento do discurso dos programas desenvolvidos pelo INAN, colocando-se em foco a proteção aos grupos biológica e socialmente vulneráveis à desnutrição, o combate aos bolsões de pobreza e a redistribuição de renda. Nesse sentido, as distintas análises realizadas sobre a intervenção alimentar e nutricional da Ditadura Militar tendem a enfatizar, particularmente, a sua dimensão ideológica. Tal dimensão é evidenciada 
não apenas no discurso social progressista que as políticas sociais utilizaram - a integração social dos contingentes populacionais que ficaram à margem do crescimento econômico, mas no próprio funcionamento desses programas, marcados pelo assistencialismo, paternalismo e clientelismo político-eleitoral. Por outro lado, se faz necessário apontar outras dimensões contidas no desempenho desses programas ao longo dos vinte anos de planejamento autoritário. Em relação aos aspectos econômicos, é preciso enfatizar a contribuição desses programas ao processo de redistribuição indireta de renda, bem como ao estímulo à ampliação e/ou garantia de mercado institucional no campo da alimentação e nutrição. Ressalta-se, por exemplo, o nítido crescimento que as indústrias de alimentos envolvidas com o mercado das políticas públicas do setor obtiveram nesses anos. De forma semelhante, vale apontar algumas hipóteses que atribuem a melhoria do estado nutricional da população brasileira, verificada entre o período 1975-1989, a um aumento moderado da renda familiar associado à expansão da cobertura dos serviços e programas sociais, entre esses os programas de alimentação e nutrição ${ }^{1,6-9,26}$. Sendo assim, estudos apontam que nesse intervalo de quinze anos, a prevalência de desnutrição entre crianças de um a quatro anos de idade foi reduzida de 19,8\% para 7,6\%, enquanto a prevalência de obesidade nessa faixa etária manteve-se inalterada (4,6\%). De forma semelhante, nesse mesmo período, a prevalência de adultos desnutridos foi reduzida de $8,6 \%$ para $4,2 \%$, enquanto a prevalência de obesidade nesse grupo etário passou de 5,7\% para 9,6\% ${ }^{26}$.

Ressalta-se ainda que, por meio do II PRONAN, a questão nutricional voltou a assumir um lugar de destaque na agenda pública, constituindo um dos principais instrumentos da política social conduzida pelos governos militares. Ou seja, por meio do II PRONAN o Estado brasileiro reatava a sua simbiótica, proveitosa e pontual união com o campo da Nutrição, cujo início se deu ao longo da Ditadura Vargas e o rompimento, ocorrido com a morte desse presidente do País, já durava cerca de 20 anos. Coincidentemente com a instituição do II PRONAN, um outro médico pernambucano voltava a ocupar o posto mais elevado da principal agência pública do campo da Nutrição no Brasil(2). Além disso, foi a partir do desenvolvimento dos programas do ॥ PRONAN que ocorreu o processo de institucionalização de ações de Nutrição no interior da rede pública de serviços de saúde, educação e assistência social em todo o território nacional.

\section{Fome, cidadania, solidariedade, focali- zação e inclusão social (1985 a 2003)}

A eleição, em 15 de janeiro de 1985, pelo Colégio Eleitoral, do falecido presidente Tancredo Neves expressa o fim da Ditadura Militar do pós-64 e o início de um novo contexto histórico, denominado de Nova República ${ }^{27}$. Explorando as contradições do modelo de desenvolvimento econômico do pós-64 nascia a Nova República e com ela a esperança de resolução de todos os problemas nacionais. Resgatavam-se velhas palavras de ordem como justiça social, liberdade política e resgate da dívida social; recuperavam-se os símbolos nacionais como a bandeira e o hino nacional e o orgulho de ser brasileiro; criava-se o pacto social, assim definido pelo seu idealizador:

[...] Nós não temos o direito de exigir dos trabalhadores qualquer cota de sacrifício em termos de restrições aos seus vencimentos ou às suas atividades funcionais. Eles já 'cortam na própria carne' para terem assegurada sua sobrevivência. Mas eles podem dar uma contribuição muito importante não só em termos de comportamento social, mas uma contri-

(2) Trata-se do Dr. Bertoldo Kruse Grande de Arruda, que presidiu o INAN no período de 1974-1984. Antes disso, outras agências da política de alimentação e nutrição, tais como o SAPS e a CNA, haviam sido presididas por Josué de Castro. Ressalta-se que em 1964, com a instalação da Ditadura Militar, Josué de Castro foi exilado do país, falecendo em Paris no ano de $1973^{\text {, }}$ 
buição mais efetiva, no sentido de aumento da produtividade, coisas conduzidas nestes termos (Tancredo Neves apud Bendetson ${ }^{28}$, p.24).

Analisando esse contexto, observa-se que a intervenção estatal na área de alimentação e nutrição apresentou-se como uma das prioridades políticas nos dois primeiros anos da Nova República; sofreu algumas alterações operacionais e constituiu um dos principais instrumentos de legitimidade do projeto de transição democrática. Assim, no ano de 1985, três instrumentos específicos de política social foram lançados: o Plano Subsídios para a Ação Imediata contra a Fome e o Desemprego, elaborado pela Comissão para o Plano do Governo (COPAG); as Prioridades Sociais para 1985 e as Prioridades Sociais para 1986. Entretanto, entre 1987 e 1989, em função da edição do Plano Cruzado (fevereiro de 1986), do Plano Bresser (julho de 1987) e do Plano Verão (fevereiro de 1989), observou-se um certo esvaziamento técnico, financeiro e político dos programas de alimentação e nutrição?

Na análise do documento Subsídios para a Ação Imediata Contra a Fome e o Desemprego, observa-se que o discurso ideológico revestia-se de um novo caráter. As palavras "fome" e "desemprego", que estiveram ausentes no discurso do planejamento autoritário da Ditadura Militar, passavam a fazer parte do novo discurso. Portanto, o resgate da fome e a sua incorporação aos instrumentos de política social eram inovadores e audaciosos e se coadunavam com a própria fala do novo presidente, que quando da sua eleição, afirmava:

Retomar o crescimento econômico e criar empregos. Toda a política econômica do meu governo estará subordinada a esse dever social. Enquanto houver neste país um só homem sem trabalho, sem pão, sem teto e sem letras, toda a prosperidade será falsa (Tancredo Neves apud Diretrizes Gerais de Política Econômica para o I PND da Nova República, O Norte ${ }^{29}$, p.9).
Entretanto, na análise das Prioridades Sociais para 1985, a primeira observação que chama a atenção é a forma sutil como as palavras "Fome" e "Desemprego" foram substituídas. Em seguida, o que chama atenção são as categorias discursivas apresentadas: democratização substantiva da sociedade; ampliação das bases do consenso social; eliminação das desigualdades e extensão dos direitos sociais fundamentais ${ }^{30}$. Essas seriam as principais categorias do discurso ideológico da Nova República. Nas Prioridades Sociais para 1985, em relação aos programas prioritários de alimentação e nutrição, além de prevista a continuidade do PNS, do PNAE, do PAT, do PROAB e do Programa de Reforço Alimentar de Creches da LBA, foi proposta a criação de um novo programa: o Programa de Abastecimento Popular (PAP) (Anexo 1) $)^{30}$.

Analisando as Prioridades Sociais para 1986 observa-se que, em linhas gerais, as suas estratégias operacionais seguem as mesmas diretrizes do programa anterior. O aperfeiçoamento do discurso ideológico, entretanto, pode ser observado a partir da incorporação de novas categorias discursivas, tais como igualdade de direitos, universalização, cidadania, opção pelos mais pobres, erradicação da pobreza e prioridade do social sobre o econômico. Em relação às prioridades na área de alimentação e nutrição, cinco programas foram previstos para 1986: o PAP; o Programa de Suplementação Alimentar (PSA); o PNAE; o Reforço Alimentar ao Programa de Creches da LBA e o Programa Nacional do Leite para Crianças Carentes (PNLCC) (Anexo 1), o qual se constituía na principal inovação da Nova República nesse campo ${ }^{31}$.

Nos últimos três anos da Nova República (1987 a 1989), as prioridades sociais foram diluídas em função dos sucessivos planos visando à estabilização econômica do país. Ao final desse período, entretanto, cinco programas de alimentação e nutrição continuavam em funcionamento: PNAE, PSA, PCA, PNLCC e PAT. Além desses, continuavam os programas da linha de complementação e apoio coordenados pelo INAN: 
Combate à Anemia Nutricional e à Hipovitaminose $\mathrm{A}$; Combate ao Bócio; Combate à Cárie Dental; Incentivo ao Aleitamento Materno e o Sistema de Vigilância Alimentar e Nutricional (SISVAN). Por outro lado, extinguiram-se o PAP (1988) e o PROAB (1989)32.

Em 16 de março de 1990 tiveram início o Governo Fernando Collor e as primeiras tentativas de implantação das idéias neoliberais de reforma do Estado. Ao analisar o período março de 1990 a 29 de setembro de 1992, verifica-se que, dentro do discurso da estabilização econômica, da modernização do Estado e da economia, o Brasil Novo, desencadeou uma brutal redução dos recursos financeiros, esvaziamento e/ou extinção dos programas de alimentação e nutrição. Além disso, esses programas também se tornaram alvo dos desvios de verbas públicas, de licitações duvidosas e de outros mecanismos ilícitos que caracterizaram a escandalosa corrupção instalada no interior daquele governo. Investigações da Comissão Parlamentar de Inquérito da Câmara dos Deputados (CPI da Fome) e auditorias do Tribunal de Contas da União (TCU) realizadas nesse período evidenciaram irregularidade no PNAE, no PSA, no PCA, no PNLCC e noutros programas $^{32,33}$

Vale ressaltar que, em março de 1990, o governo nomeou para presidente do INAN um representante da Associação Brasileira da Indústria de Nutrição (ABIN), o qual passou a priorizar, nitidamente, os interesses dos produtores de alimentos formulados. Assim, o PSA passou a substituir os tradicionais alimentos básicos por produtos industrializados (fiambre bovino, macarrão de milho, leite desnatado enriquecido), enquanto o PNAE interrompia o processo de municipalização, voltando a distribuir produtos formulados. Por outro lado, em janeiro de 1991, o governo anunciou a extinção do PNLCC, denotando interesses muito mais político-ideológicos do que técnico-operacionais e econômicos. O fato é que, mesmo sob a coordenação da LBA, presidida pela primeira dama do país, o PNLCC continuou sendo identificado com o seu criador (o presidente Sarney). E o governo Collor, seguindo as características de descontinuidade dos programas sociais, procurava legitimidade e hegemonia a partir de outros mecanismos. Nesse sentido, a LBA passou a divulgar uma série de alterações nos programas, como a substituição do PCA pelo Programa de Apoio Nutricional (PAN) e pelos Centros de Atenção ao Desnutrido (CAD), extinguindo a distribuição de alimentos formulados e a criação do programa de distribuição de cestas básicas (Minha Gente ou Gente da Gente), o qual se transformaria em Programa de Distribuição Emergencial de Alimentos (PRODEA), em 1993 (Anexo 1). No caso do PAT, observou-se que o programa permaneceu concentrado no Sudeste e Sul do país, atendendo prioritariamente as grandes e médias empresas e os trabalhadores com melhores condições de renda ${ }^{32}$.

No decorrer de 1992, diante do agravamento da crise ética verificada no interior da política brasileira, entidades da sociedade civil constituíram o chamado Movimento pela Ética na Política, cujo objetivo inicial era "aglutinar as esperanças e ações de todo o povo na direção de uma política guiada por valores éticos em favor da justiça social, da solidariedade e da vida"34 (p.1). Com a aprovação do histórico impeachment do presidente Collor, o Movimento pela Ética na Política deu origem a uma outra cruzada ética: a constituição do movimento social Ação da Cidadania Contra a Fome, a Miséria e pela Vida. Liderado por Betinho, o movimento foi lançado oficialmente em 8 de março de 1993, tendo como objetivo "mobilizar, e acima de tudo, sensibilizar a sociedade para a necessidade de mudanças fundamentais e urgentes capazes de transformar a realidade econômica, política e social do país [...] que leva à exclusão, à fome e à miséria" 35 , (p.12).

Para consecução desse seu objetivo, iniciou-se o processo de formação dos Comitês de Combate à Fome. Esses comitês, de abrangência local, municipal e/ou estadual, poderiam ser formados por amplos e diversificados setores da sociedade, denotando o caráter de pluralidade do movimento. Coordenados pela Secretaria 
Executiva Nacional da Ação da Cidadania, cada comitê teve como tarefa básica a articulação de dois tipos de ações em seu âmbito territorial: ações emergenciais e ações de pressão de opinião pública. Assim, no decorrer de 1993, de acordo com dados oficiais, foram constituídos mais de cinco mil comitês ${ }^{2,34,35}$.

Por outro lado, no âmbito da sociedade política, em 18 de março de 1993, o presidente Itamar Franco assumiu o compromisso de implantação da Política Nacional de Segurança Alimentar ${ }^{36}$ apresentada pelo presidente do Partido dos Trabalhadores (PT). Em 18 de abril de 1993 foram lançados o Plano de Combate à Fome e à Miséria e a proposta de constituição do Conselho Nacional de Segurança Alimentar (CONSEA). O CONSEA, instituído por Decreto Presidencial, em 26 de abril de 1993, foi formado por nove Ministros de Estado e 21 representantes da sociedade civil, com o objetivo de assessorar o governo na formulação de propostas e implementação de ações em busca de soluções para o problema da fome e da miséria no Brasil. A partir de então, no decorrer do governo Itamar Franco (1993-1994), a chamada parceria entre governo e sociedade, caracterizada pela ação conjunta do CONSEA/Ação da Cidadania, desenvolveu numerosas atividades, em sua grande maioria de caráter emergencial, na tentativa de combate à fome e à miséria do país 2,35,37.

Vale ressaltar que, no início dos anos 1990, ao mesmo tempo em que a Ação da Cidadania e o Plano de Combate à Fome e à Miséria chamavam a atenção para os 32 milhões de pobres e famintos existentes no país, outros segmentos da sociedade brasileira começavam a alertar para os chamados fenômenos da transição epidemiológica e da transição nutricional no Brasil. Sendo assim, a partir dos resultados da Pesquisa Nacional sobre Saúde e Nutrição (PNSN), realizada em 1989, e de outros estudos realizados no país, cientistas brasileiros começavam a alertar para a sensível redução da prevalência das doenças nutricionais relacionadas à fome e à miséria (desnutrição energético-protéica, hipovitaminose $A$, anemia ferropriva e bócio endêmico) e, simultaneamente, para a sensível elevação da prevalência da obesidade e outras doenças crônicas não transmissíveis, tais como diabetes mellitus, cardiopatias, osteoporose, dislipidemias e neoplasias ${ }^{38,39}$.

No início de 1995, o esvaziamento da Ação da Cidadania tornou-se evidente. As primeiras ações do governo Fernando Henrique Cardoso (FHC) foram a criação do Programa Comunidade Solidária, pelo Decreto no 1.366, de 12/01/95, a extinção do CONSEA e a criação do Conselho do Comunidade Solidária, tendo como presidente a primeira dama do país, Ruth Cardoso 2,40.

Ao ser lançado, o Programa Comunidade Solidária apresentava-se como uma nova estratégia de combate à pobreza e à exclusão social, com objetivo de unir os esforços e os recursos disponíveis no governo e na sociedade civil na busca de soluções mais eficientes e eficazes para a melhoria da qualidade de vida das populações mais pobres. Portanto, não se tratava de um programa com caráter executivo, mas de uma nova estratégia de gerenciamento dos programas sociais, cuja intervenção pautava-se em quatro princípios básicos: parceria, solidariedade, descentralização e integração/ convergência das ações. A sua estrutura operacional foi composta por uma Secretaria-Executiva e por um Conselho Consultivo. À SecretariaExecutiva competia a coordenação e o acompanhamento das ações governamentais nas áreas de maior concentração de pobreza, por meio de programas nos campos da alimentação, assistência social, educação, geração de emprego e renda e saúde. O Conselho Consultivo, nomeado pelo presidente da República e vinculado à Casa Civil, era integrado por dez ministros de Estado, vinte e um representantes da sociedade civil e uma Secretaria Executiva. Ao Conselho Consultivo competia a mobilização da sociedade civil, potencializar suas iniciativas, divulgar experiências bem sucedidas e promover parcerias entre os segmentos da sociedade ${ }^{40,41}$.

No primeiro governo FHC (1995-1998), observou-se que os programas de alimentação e nutrição até então existentes continuaram sendo 
desenvolvidos dentro dos moldes operacionais dos governos anteriores. Ao final desse período continuavam em funcionamento: o PNAE; O PAT; o Programa Leite é Saúde, que passou a se chamar Programa de Combate às Carências Nutricionais (PCCN) e depois Incentivo ao Combate às Carências Nutricionais (ICCN); o PRODEA; os demais programas voltados ao combate às carências nutricionais específicas e o SISVAN (Anexo1). Sem dúvida, a grande alteração verificada nesses anos foi a extinção do INAN, por meio da Medida Provisória oㅜ 1.576, de 5 de junho de 19972,42.

No segundo governo FHC (1999-2002), vale destacar a emissão da Portaria no 710 do Ministério da Saúde, de 10 de junho de 1999, que aprova a Política Nacional de Alimentação e Nutrição (PNAN) e a adoção da Medida Provisória no 2.206, de 10 de agosto de 2001, que cria o Programa Nacional de Renda Mínima vinculado à Saúde (Bolsa Alimentação). Em relação à Política Nacional de Alimentação e Nutrição, pode-se dizer que se tratou de uma importante estratégia da Coordenação-Geral da Política de Alimentação e Nutrição (CGPAN), órgão vinculado à Secretaria de Políticas de Saúde do Ministério da Saúde, criado em 1998, o qual passou a desempenhar as competências, direitos e obrigações do extinto INAN, no sentido de estabelecer diretrizes específicas de alimentação e nutrição dentro do setor saúde. Contando com a participação de representantes de distintos segmentos da sociedade civil e política, foram estabelecidas sete diretrizes para a condução da PAN ${ }^{43}$. O Programa Bolsa Alimentação, por sua vez, desenvolvido sob a responsabilidade da CGPAN, visa à promoção das condições de saúde e nutrição de gestantes, nutrizes e crianças de seis meses a seis anos e onze meses de idade, em risco nutricional, pertencentes a famílias sem renda ou que possuam renda mensal de até $R \$ 90,00$ per capita, mediante a complementação da renda familiar para a melhoria da alimentação e o fomento à realização de ações básicas de saúde. Cada família beneficiária recebe de $R \$ 15,00$ a $R \$ 45,00$ por mês, dependendo do número de beneficiários, por meio de saque com cartão magnético em agências da Caixa Econômica Federal ${ }^{44}$. Além disso, ao longo dos anos 1999-2002, observaram-se um progressivo esvaziamento da atuação do Comunidade Solidária no campo do combate à fome, a extinção do PRODEA e a substituição do ICCN pelo Bolsa Alimentação. Portanto, ao final do governo FHC, a CGPAN responsabilizava-se pela condução dos programas vinculados ao setor saúde (Bolsa Alimentação; Ações de Controle da Hipovitaminose A, Anemia Ferropriva e Distúrbios por Deficiência de lodo; Ações para promoção da Alimentação Saudável e SISVAN); o Fundo Nacional de Desenvolvimento da Educação (Ministério da Educação) pela condução do PNAE e a Secretaria de Inspeção do Trabalho (Ministério do Trabalho) pela condução do PAT (Anexo 1) ${ }^{42,44}$.

Ao longo de 2001, militantes e simpatizantes da campanha de Luís Inácio Lula da Silva à presidência da República, reunidos em diversos encontros, elaboraram o Projeto Fome Zero: Uma proposta de Política de Segurança Alimentar para o Brasil42, lançado em 16 de outubro 2001. O projeto se constituiu em um dos instrumentos da campanha vitoriosa do candidato e nas bases do Programa Fome Zero, lançado em 31 de janeiro de 2003. Em 1o de janeiro de 2003, no discurso da cerimônia de posse realizada no Congresso Nacional, foi assim referendado pelo presidente Lula como umas das prioridades do seu governo:

[...] Por isso, defini entre as prioridades de meu governo um programa de segurança alimentar que leva o nome de "Fome Zero". Como disse em meu primeiro pronunciamento após a eleição, se, ao final do meu mandato, todos os brasileiros tiverem a possibilidade de tomar café da manhã, almoçar e jantar, terei cumprido a missão da minha vida.

É por isso que hoje conclamo: Vamos acabar com a fome em nosso País. Transformemos o fim da fome em uma grande causa nacional, como foram no passado a criação da Petrobrás e a memorável luta pela redemocratização do País. Essa é uma causa que pode e 
deve ser de todos, sem distinção de classe, partido, ideologia. Em face do clamor dos que padecem o flagelo da fome, deve prevalecer o imperativo ético de somar forças, capacidades e instrumentos para defender o que é mais sagrado: a dignidade humana ${ }^{45}$ (p.8).

Na seqüência da solenidade de posse, no discurso realizado no Parlatório do Planalto, o presidente reafirmava à Nação:

[...] E quero propor isso a vocês: amanhã, estaremos começando a primeira campanha contra a fome neste país. É o primeiro dia de combate à fome. E tenho fé em Deus que a gente vai garantir que todo brasileiro e brasileira possa, todo santo dia, tomar café, almoçar e jantar, porque isso não está escrito no meu programa, isso está escrito na Constituição Brasileira, está escrito na Bíblia e está escrito na Declaração Universal dos Direitos Humanos. E isso nós vamos fazer juntos $^{46}$ (p.31).

Retirando-se o excesso de entusiasmo do discurso do novo presidente, ao afirmar que estava começando a primeira campanha contra a fome no Brasil, verifica-se, com a criação do Fome Zero, não o início, mas a reinserção do discurso do pacto social, combate à fome e à miséria, direito à alimentação e segurança alimentar como prioridades da agenda pública brasileira para os próximos quatro anos.

A partir de uma leitura inicial, percebe-se que o Programa Fome Zero é composto por um conjunto de ações que se dizem integradas com o objetivo de erradicação da fome e implementação da política de segurança alimentar e nutricional no país. Tais ações, que estão sendo executadas de forma gradativa, agrupam três modalidades de intervenção denominadas de políticas estruturais, políticas específicas e políticas locais. As políticas estruturais são definidas como aquelas que objetivam atingir a raiz do problema da fome e da pobreza, sendo categorizadas como: geração de emprego e renda; previdência social universal; incentivo à agricultura familiar; intensificação da reforma agrária; bolsa-escola e renda mínima; segurança e qualidade dos alimentos. As políticas específicas são concebidas como intervenções nutricionais de natureza emergencial voltadas ao equacionamento de situações agudas de fome e miséria, sendo categorizadas nas modalidades: Programa Cartão-Alimentação, Alimentos Emergenciais, Estoques de Alimentos de Segurança, Educação para o Consumo Alimentar, Ampliação do Programa de Alimentação do Trabalhador, Combate à Desnutrição e Ampliação do Programa de Alimentação Escolar. As políticas locais são definidas como intervenções que visam à integração e adaptação de experiências municipais e/ou estaduais bem sucedidas, sendo categorizadas como: programas para áreas rurais, programas para pequenas e médias cidades e programas para metrópoles. Para o cumprimento dos seus objetivos, em sua estrutura operacional o programa envolve todos os ministérios e a estrutura do Ministério Extraordinário de Segurança Alimentar e Combate à Fome (MESA), além de um conselho consultivo. O CONSEA, criado a partir da Medida Provisória no 102 de 1o de janeiro de 2003 e regulamentado pelo Decreto $n-4.582$, de 30 de janeiro de 2003, constitui um órgão de caráter consultivo e de assessoria imediata ao Presidente da República, tendo como objetivo propor as diretrizes gerais da Política Nacional de Segurança Alimentar e Nutricional. O CONSEA foi composto por 62 conselheiros, nomeados pelo presidente da República, sendo 13 ministros de Estado, 11 observadores e 38 representantes da sociedade civil. Além disso, o Fome Zero definiu como público potencial de suas propostas estruturais e emergenciais, cerca de 46 milhões de brasileiros que dispõem de menos de um dólar per capita/dia para sobreviver (Anexo 1). Entretanto, de acordo com o seu site oficial, o programa apenas terá seu detalhamento concluído com a elaboração e aprovação do Plano Plurianual para 2004-200742,47-49.

Em síntese, nesse terceiro corte analisado (1985-2003), correspondente aos governos José Sarney, Fernando Collor/ltamar Franco, Fernando 
Henrique Cardoso e ao primeiro ano de Luís Inácio Lula da Silva, observa-se que o discurso de combate à fome reaparece no cenário nacional durante a campanha das Diretas Já (1984), sendo oficializado pelo do Plano Subsídios para a Ação Imediata Contra a Fome e o Desemprego do presidente Tancredo Neves. Análises realizadas sobre a intervenção nutricional da Nova República apontam no discurso das Prioridades Sociais, do tudo pelo social, o resgate de mecanismos populistas visando estabelecer laços simbólicos entre o presidente e o povo (os beneficiários dos programas). A partir desse discurso a Nova República estabeleceu um neopopulismo em torno da determinação da miséria e da fome e suas formas de enfrentamento, criando os seus instrumentos de geração de legitimidade e hegemonia. Por outro lado, observou-se a criação de novos e importantes mecanismos de funcionamento dos programas, a exemplo do PNLCC, que introduziu o sistema de distribuição de tickets, e o envolvimento das associações comunitárias na execução do programa. Em relação à organização administrativa, vale ressaltar o importante avanço ocorrido em alguns programas, tais como o PNAE e o PSA, os quais, gradativamente, passaram do sistema de centralização à descentralização de suas estruturas operacionais. Além disso, cabe destacar a débil tentativa de implementação de um sistema de monitoramento da situação alimentar e nutricional de determinados grupos populacionais, conhecido como Sistema de Vigilância Alimentar e Nutricional (SISVAN) ${ }^{32,50-52}$.

Na seqüência, nos anos 1990-1994 verificou-se uma nova redescoberta da fome no país e a implementação de intervenções nutricionais governamentais e não governamentais tendo como principais categorias discursivas: solidariedade, parceria, descentralização e segurança alimentar ${ }^{2,35,37}$. No âmbito da sociedade civil, a histórica mobilização nacional concretizada pela Ação da Cidadania, cujos sinais de vitalidade continuam até os dias de hoje, atesta a singularidade desse movimento. O impacto das suas realizações no combate à fome e à miséria no país, entretanto, precisa ser mais bem investigado.

Por outro lado, no decorrer do governo FHC (1995-2002), por meio da Comunidade Solidária, identificaram-se a ênfase no discurso neoliberal da focalização, flexibilidade e parcerias entre o estado mínimo, o mercado e o chamado terceiro setor $^{40}$. Uma série de críticas foram feitas ao Comunidade Solidária e, particularmente, à composição e à forma de atuação do seu Conselho Executivo. Em linhas gerais, estas críticas apontam as alterações substanciais ocorridas na forma de concepção, orientação e gerenciamento das políticas públicas entre esse programa e o CONSEA, o que, inclusive, teria provocado o desligamento de Betinho do referido conselho. Entretanto, pode-se afirmar que com a Comunidade Solidária avançou a tendência que vinha se configurando no âmbito das políticas sociais, desde anos anteriores, com sensível redução da intervenção estatal direta e ampliação do papel do chamado terceiro setor, caracterizado particularmente pela proliferação da atuação das Organizações Não-Governamentais (ONG). Além disso, ao final do governo FHC destaca-se a introdução de uma nova modalidade de intervenção nutricional no país, baseada no mecanismo de transferência direta de renda, a partir da criação do Programa Bolsa Alimentação 2,42,53.

Por último, ressalta-se que no primeiro ano do governo Lula, entre o clima de euforia da divulgação e a demora na execução das primeiras ações do Programa Fome Zero, gerou-se um espaço propício para críticas e especulações, particularmente para o caráter assistencialista das atividades iniciais anunciadas (as doações). De fato, observou-se uma intensa propaganda governamental para sensibilizar a população em torno do Fome Zero e, inicialmente, parece ter ocorrido uma adequada adesão da sociedade civil e de empresários ao programa. Ao final do primeiro ano, entretanto, a extinção do MESA e a transferência da coordenação do Fome Zero para um novo ministério constituem os principais indícios da duvidosa eficácia das ações até então desenvolvidas pelo programa ${ }^{47-49}$. 


\section{CONSIDERAÇÕES FINAIS}

A análise da política de alimentação e nutrição no Brasil, ao longo da trajetória examinada (1930 a 2003), aponta não apenas as mudanças, rupturas, retrocessos e avanços ocorridos na forma de concepção, orientação, gerenciamento e implementação da política e dos programas de combate à fome. Além dessas alterações, identificam-se aquelas que se processaram na estrutura de morbidade populacional, na conformação do tecido social e na forma e conteúdo do Estado brasileiro.

Em relação às alterações verificadas na estrutura de morbidade populacional, processo conhecido como transição epidemiológica, ao longo do período examinado observou-se uma sobreposição de doenças relacionadas à miséria, à pobreza e ao atraso econômico e doenças associadas à riqueza, ao avanço tecnológico e à modernidade. No caso das alterações ocorridas no perfil de morbidade nutricional, processo conhecido como transição nutricional, o grupo de doenças relacionadas à fome e à miséria tem apresentado sensíveis reduções em suas prevalências. Por outro lado, o grupo relacionado ao excesso de consumo alimentar vem assumindo índices alarmantes, constituindo os principais problemas de saúde pública da contemporaneidade ${ }^{38,39}$. Análises sobre a evolução de déficits antropométricos em crianças menores de cinco anos, entre o período de 1989 e 1996, apontam que os índices estatura/idade, peso/idade e peso/estatura (valores abaixo de 2 desvios-padrão da média esperada para idade e sexo) passaram, respectivamente, de $15,7 \%$ para $10,5 \%$, de $7,2 \%$ para $5,7 \%$ e de $2,0 \%$ para $2,3 \%$, confirmando a tendência de melhoria do estado nutricional verificada desde as décadas anteriores ${ }^{26}$. Para a faixa etária de seis a dezoito anos de idade, estudo realizado entre o período de 1975 a 1997, com base em valores do índice de massa corporal (IMC), indica que a prevalência de baixo peso (desnutrição) foi reduzida de 14,8\% para 8,6\%, ao passo que a de sobrepeso (obesidade) foi elevada de $4,1 \%$ para $13,9 \%{ }^{54}$. De forma semelhante, para a população acima de 20 anos de duas regiões brasileiras (Nordeste e Sudeste) verificou-se, entre 1975 a 1997, a mesma tendência de elevação da obesidade, diagnosticada a partir do índice de massa corporal. Sendo assim, entre 1975 e 1997, os índices de obesidade entre as populações masculina e feminina da região Nordeste passaram, respectivamente, de 1,3\% para $4,4 \%$ e de $4,2 \%$ para $12,2 \%$. Na região Sudeste, nesse mesmo período, a obesidade entre as populações masculina e feminina passou, respectivamente, de $2,9 \%$ para $8,2 \%$ e de $8,0 \%$ para $12,6 \%{ }^{26}$.

Ao longo do período examinado, as mudanças de forma do Estado Brasileiro possibilitaram o processo de transição do Estado Intervencionista, cuja conformação teve início no pós-30, ao chamado Estado Mínimo ou Neoliberal, o qual a partir de meados dos anos 1980 tem assumido crescente configuração. Simultaneamente, ao longo das distintas conjunturas analisadas, o Estado Brasileiro também transitou por distintas formas históricas e conteúdos específicos, deslocando-se da centralização à descentralização; da tecnoburocracia civil à militar; do autoritarismo à democracia; do populismo nacionalista ao desenvolvimentismo; da intervenção na economia à liberalização do mercado $^{11,12}$.

Nesse sentido, também é possível afirmar que o processo de construção, desconstrução e/ou reconstrução da política social de alimentação e nutrição acompanhou, de forma articulada, as mudanças ocorridas ao longo desses setenta anos de modernização conservadora da sociedade brasileira. Ao longo da trajetória investigada, sobretudo a partir de meados dos anos 1980, as categorias discursivas e operacionais da política e dos programas de combate à fome no país têm transitado do planejamento autoritário ao participativo; da centralização à descentralização administrativa; da universalização à focalização de benefícios; do controle estatal ao social; dos programas de distribuição de alimentos em espécie aos de tickets e aos de transferência de renda 
em dinheiro; do financiamento público às parcerias entre publico e privado, entre sociedade civil e Estado, entre instituições governamentais e não governamentais; das ações emergenciais ou assistenciais às mediatas ou estruturais; das ações compensatórias às de emancipação.

Conforme Anexo 1, ao final do período investigado, três modalidades de programas continuam em funcionamento: o PNAE, o PAT e o Programa de Combate às Carências Nutricionais Específicas (anemias nutricionais, hipovitaminose A e bócio). A partir de 2003, a esses se agregam outras modalidades iniciadas com a instituição do Programa Fome Zero. O PNAE (1954 até hoje) se constitui no programa de maior longevidade da trajetória da política social de alimentação e nutrição brasileira. O PAT (1976 até hoje) representa o segundo programa de maior longevidade. E os Programas de Combate às Carências Nutricionais Específicas, consolidados a partir do II PRONAN, embora caracterizados pelo desenvolvimento de ações pontuais e localizadas (com exceção do Programa de Combate ao Bócio, cujas ações têm um caráter de abrangência nacional), aparecem em terceiro lugar em termos de vigência.

Os demais programas arrolados, particularmente aqueles destinados à assistência alimentar e nutricional do grupo materno infantil (gestantes, nutrizes e crianças menores de cinco anos de idade), caracterizaram-se como experiências efêmeras, cujas vigências se localizaram apenas em determinados governos ou conjunturas. De forma semelhante, cabe apontar o processo de descontinuidade e alternância verificado entre as agências condutoras da política de alimentação e nutrição (SAPS, CNA e INAN), analisadas ao longo do período. Observa-se, portanto, que o período de vigência dessas três agências, entre 25 a 27 anos, denota, por si mesmo, o processo de instabilidade institucional da política social de alimentação e nutrição do país.

Em função do longo eixo longitudinal investigado, tornam-se evidentes as limitações do presente artigo no que tange à realização de uma análise mais aprofundada e comparativa dos distintos programas e agências de alimentação e nutrição, bem como dos possíveis impactos desses programas na melhoria do estado nutricional da população brasileira. Tarefa essa imprescindível, mas que ainda está por vir.

Enfim, após um ano de expectativa em torno do Programa Fome Zero, por enquanto, resta continuar lutando para que as necessárias medidas estruturais, associadas às emergenciais, sejam colocadas em ação, e esperar que a histórica fome estrutural do povo brasileiro seja definitivamente superada.

\section{REFERÊ NCIAS}

1. Coutinho AON. Alimentação do brasileiro: uma visão histórica. Rev Saúde Debate. 1988; 13(23):32-9.

2. Valente FLS. Do combate à fome à segurança alimentar e nutricional: o direito à alimentação adequada. Rev Nutr. 1997; 10(2):20-36.

3. Freyre G. Casa-grande \& senzala. 34.ed. Rio de Janeiro: Record; 1998.

4. Vasconcelos FAG. O nutricionista no Brasil: uma análise histórica. Rev Nutr. 2002; 15(2):127-38.

5. Castro J. Geografia da fome: o dilema brasileiro: pão ou aço. 10.ed. Rio de Janeiro: Antares; 1980.

6. Coimbra M, Meira JFP, Starling MBL. Comer e aprender: uma história da alimentação escolar no Brasil. Belo Horizonte: MEC/INAE; 1982.

7. L'Abbate $S$. As políticas de alimentação e nutrição no Brasil. I. Período de 1940 a 1964. Rev Nutr. 1988; 1(2):87-138.

8. Natal JLA. A questão alimentar-nutricional na política econômica (1930-1976): um vai-vem na periferia da agenda pública [dissertação]. Campinas: Universidade Estadual de Campinas; 1982.

9. Vasconcelos FAG. A Política social de alimentação e nutrição no Brasil: acumulação de capital e reprodução da fome/desnutrição. Rev Saúde Debate. 1988; 13(23):42-9.

10. Faleiros VP. A política social do estado capitalista: as funções da previdência e assistência sociais. 7.ed. São Paulo: Cortez; 1995.

11. Alencar F, Ramalho LC, Ribeiro MVT. História da sociedade brasileira. 15.ed. Rio de Janeiro: Livro Técnico; 1996. 
12. Ianni O. Estado e planejamento econômico no Brasil. 6.ed. Rio de Janeiro: Civilização Brasileira; 1996.

13. Castro J. As condições de vida das classes operárias no Nordeste. In: Castro J. Documentário do Nordeste. 2.ed. São Paulo: Brasiliense; 1959.

14. Saboia J. Salário mínimo: a experiência brasileira. São Paulo: L\&PM; 1985.

15. Castro AM. Nutrição e desenvolvimento: análise de uma política [tese]. Rio de Janeiro: Universidade Federal do Rio de Janeiro; 1977.

16. Brussi AJE. A santa ceia: salário e nutrição no Brasil [dissertação]. Brasília: Universidade de Brasília; 1977.

17. Departamento Intersindical de Estatística e Estudos Sócio-Econômicos. $1^{\circ}$ de maio, Dia do trabalho: a questão do salário mínimo. Boletim DIEESE, Edição especial [Internet] 2002 maio. São Paulo; 2002. [acesso 2003 maio 10]. Disponível em: http:// w.w.w.dieese.org.br/esp/ salminmai02.pdf

18. Departamento Intersindical de Estatística e Estudos Sócio-Econômicos. Apenas uma capital tem queda no preço dos alimentos básicos [Internet] [citado 2003 maio 10]. Disponível em: http://www. dieese.org.br/ rel/rac/racmai03.html

19. Associação Mundial de Luta Contra a Fome. A Luta Mundial Contra a Fome: o livro da fome. Rio de Janeiro: Serviço Gráfico do IBGE; 1957.

20. Ferreira Lima J, Mello FB, Costa F, Bancovsky J, organizadores. Aspectos do problema alimentar no Nordeste. Recife: Imprensa Universitária; 1962.

21. George S. O mercado da fome: as verdadeiras razões da fome no mundo. Rio de Janeiro: Paz e Terra; 1976.

22. Goldenberg P. Repensando a desnutrição como questão social. Campinas: Universidade Estadual de Campias; 1988.

23. Viacava F, Figueiredo CMP, Oliveira WA. A desnutrição no Brasil. Petrópolis: Vozes; 1983.

24. Coitinho DC, Leão MM, Recine E, Sichieri R. Condições nutricionais da população brasileira: adultos e idosos. Brasília: INAN; 1991.

25. Arruda BKG. Política alimentar e nutricional do Brasil [documento técnico]. Brasília: INAN; 1979.

26. Monteiro CA, organizador. Velhos e novos males da saúde no Brasil: a evolução do país e de suas doenças. São Paulo: Hucitec; 2000.

27. Falcão R. A República que fez plástica. In: Koutzii F, organizador. Nova República: um balanço. São Paulo: L\&PM; 1986.

28. Bendetson M. O Homem Tancredo. Rev Manchete. 1985; (Edição especial), 26 de janeiro. p.24.
29. Introdução da Diretrizes Gerais de Política Econômica para o I PND da Nova Republica. Jornal O Norte. 1985; (maio 18): 9.

30. Secretaria do Planejamento. Prioridades Sociais para 1985. Brasília: Coordenadoria de Comunicação Social; 1985.

31. Secretaria do Planejamento. Prioridades Sociais para 1986. Brasília: Coordenadoria de Comunicação Social; 1985.

32. Vasconcelos FAG. Acumulação de capital, corrupção e fome. Rev Saúde Debate. 1993; 18(39):48-52.

33. CPI da Fome. Comissão Parlamentar de Inquérito destinada a examinar as causas da fome e a iminente ameaça à segurança alimentar. Relatório Final. Brasília: Câmara dos Deputados; 1991.

34. Ação da Cidadania Contra a Miséria e pela Vida. Cartilha para ajudar a formar comitês. [Brasília: Secretaria Nacional da Ação da Cidadania contra a Miséria e pela Vida]; 1993.

35. Conselho Nacional de Segurança Alimentar. I Conferência Nacional de Segurança Alimentar. Relatório final. Brasília: CONSEA; 1995.

36. Silva LIL, Silva JG. Política Nacional de Segurança Alimentar. São Paulo: Governo Paralelo; 1991.

37. Peliano AMM, Beghin N. A nova experiência brasileira no combate à fome e à miséria. Rev Saúde Debate. 1993; 18(40):17-25.

38. Monteiro CA, Mondini L, Souza ALME, Popkin BM. Da desnutrição para a obesidade: a transição nutricional no Brasil. In: Monteiro CA, organizador. Velhos e novos males da saúde no Brasil: a evolução do país e de suas doenças. São Paulo: Hucitec; 2000.

39. Popkin BM. The shift in stages of the nutrition transition in the developing world differs from past experiences. Pub Health Nutr. 2002; 5(1A): 205-14.

40. Cardoso R, Franco A, Oliveira MD. 2000. Um novo referencial para a ação social do Estado e da Sociedade: sete lições da experiência da Comunidade Solidária [Internet]. Brasília. [citado 2002 fev 9]. Disponível em: http: www. comunidadesolidaria.org.br

41. Peliano AMM, Resende LFL, Beghin N. O comunidade solidária: uma estratégia de combate à fome e à pobreza. Plan Políticas Públicas. 1996; (12):19-37.

42. Silva LIL, Camargo JÁ, coordenador. Projeto Fome Zero: uma proposta de política de segurança alimentar para o Brasil. São Paulo: Instituto da Cidadania; 2001. 
43. Ministério da Saúde. Coordenação-Geral da Política de Alimentação e Nutrição. Política Nacional de Alimentação e Nutrição [Internet]. 1999. [citado 2003 maio 17]. Disponível em: http://portal.saude.gov.br/alimentacao/ politica.cfm

44. Ministério da Saúde. Coordenação-Geral da Política de Alimentação e Nutrição [Internet]. Apresentação. [acesso 2003 maio 17]. Disponível em: http://portal.saude.gov.br/alimentacao/ apresentacao.cfm

45. Silva LIL. Discurso do Senhor Presidente da República, Luiz Inácio Lula da Silva, na cerimônia de posse. Brasília, Congresso Nacional, $1^{\circ}$ janeiro 2003. [Internet] [acesso 2003 maio 14]. Disponível em: http://www. presidencia. gov.br/publi_ 04/ colecao/Dispres.pdf

46. Silva LIL. Discurso do Senhor Presidente da República, Luiz Inácio Lula da Silva, após a cerimônia de posse. Brasília, Parlatório do Palácio do Planalto, 10 janeiro 2003. [Internet] [acesso 2003 maio 14]. Disponível em: http:// www.presidencia. gov.br/ publi_04/colecao/ Dispres.pdf

47. Fome Zero. Governo faz lançamento oficial do Programa Fome Zero. [Internet] [acesso 2003 maio 17]. Disponível em: http:// www.fomezero.gov.br/ exec/noticias/ detalhe. $\mathrm{cfm} ? \operatorname{cod}=1062$
48. Fome Zero. Entenda como funciona o CONSEA. [Internet] [citado 2003 maio 17]. Disponível em: http://www.fomezero.gov.br/exec/noticias/ detalhe. $c f m ? \operatorname{cod}=1163$

49. Fome Zero. Presidente lança Programa Fome Zero e cria CONSEA. [Internet] [acesso 2003 maio 17]. Disponível em: http://www.fomezero.gov.br/exec/ noticias/detalhe. $\mathrm{cfm}$ ?cod=1164

50. Moura M. O leite das crianças ou o Leite do Presidente. Cad CEAS. 1986; (105):65-71.

51. Lechtig A, Peliano AM, Salomon JB, Neto ER. Programas de distribuição de alimentos mediante cupons: que é possível aprender dos programas implantados? Brasília: Codeplan; 1987.

52. Takagi M, Silva JG, Belik W, organizador. Combate à fome e à pobreza rural. São Paulo: Instituto Cidadania; 2002.

53. Demo P. Solidariedade como efeito de poder. São Paulo: Cortez; 2002.

54. Wang Y, Monteiro C, Popkin BM. Trends of obesity and underweight in older children and adolescents in the United States, Brazil, China, and Russia. Am J Clin Nutr. 2002; 75(6):971-7.

Recebido para publicação em 10 de março de 2004 e aceito em 10 de janeiro de 2005. 


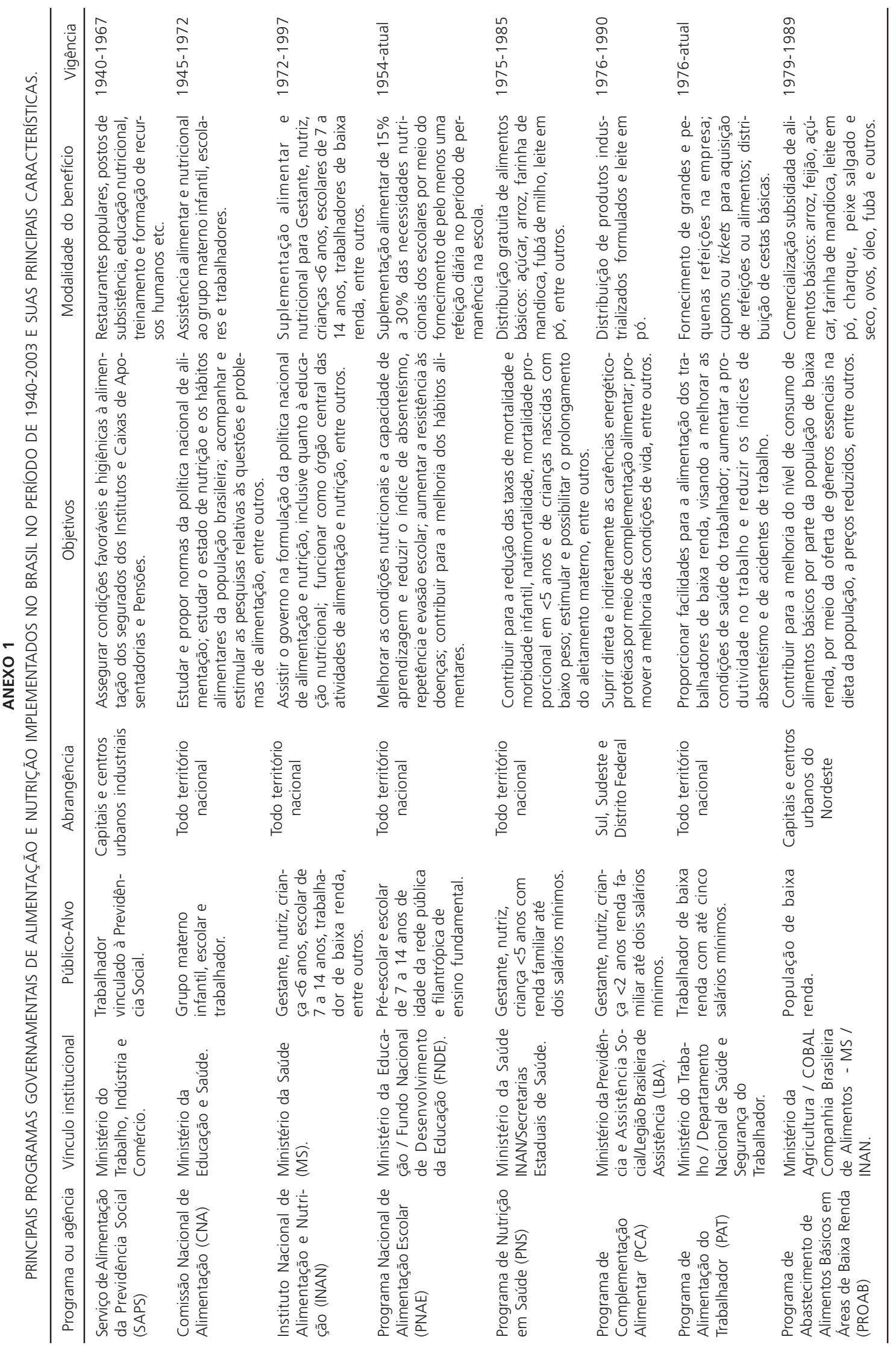




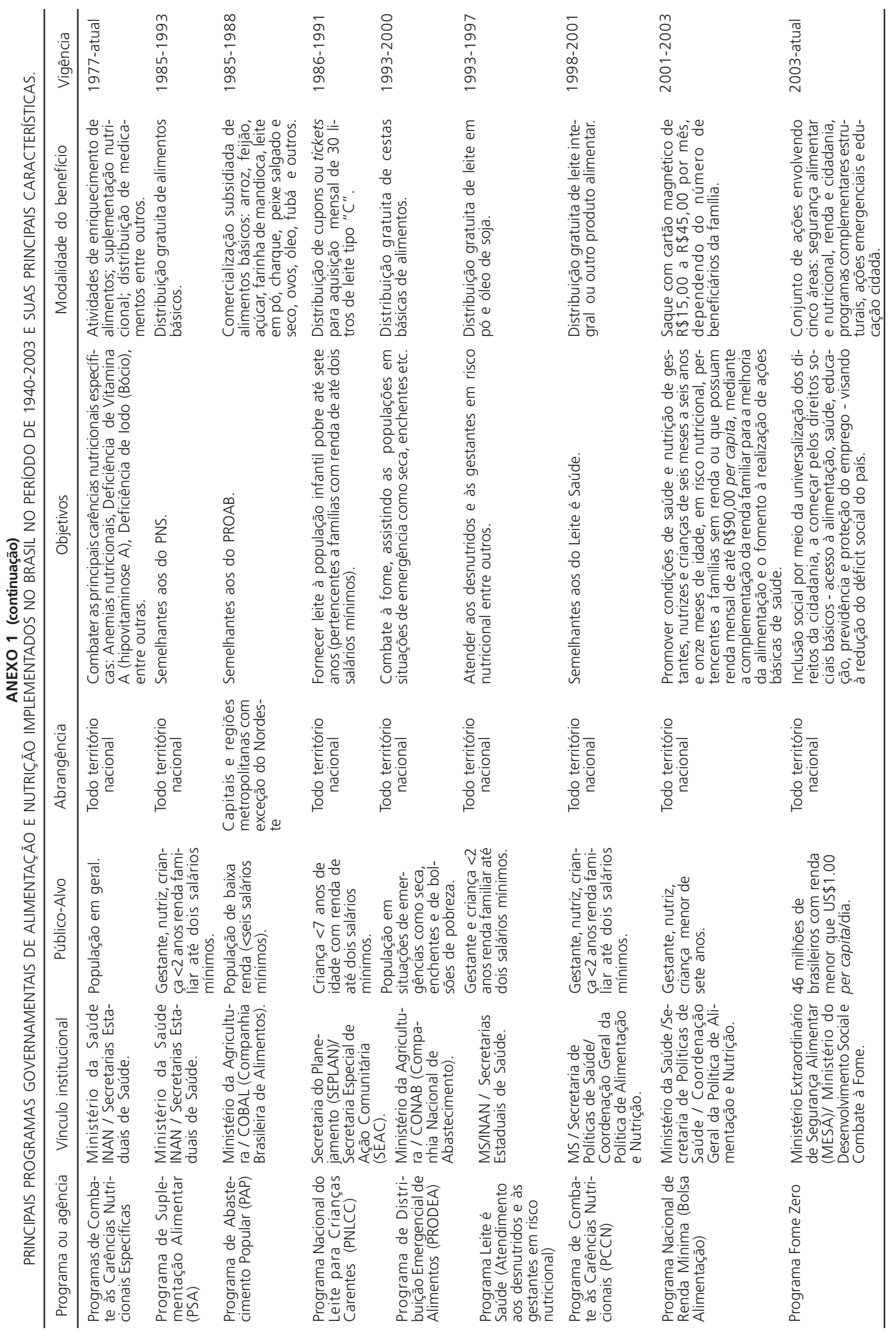

